\title{
Self-stigma and the intention to seek psychological help online compared to face-to-face
}

\section{Emma Wallin $^{1}$ (D) | Pernilla Maathz ${ }^{1}$ | Thomas Parling ${ }^{2}$ | Timo Hursti ${ }^{1}$}

\author{
${ }^{1}$ Uppsala University \\ ${ }^{2}$ Stockholm County Council \\ Correspondence \\ Emma Wallin, MS, Department of Psychology, \\ Uppsala University, Box 1225, Uppsala SE-75142, \\ Sweden. \\ Email:emma.wallin@psyk.uu.se
}

\begin{abstract}
Objectives The present study aims to investigate the impact of helpseeking self-stigma on the preference and intention to seek psychological treatment delivered online compared to face-to-face.

Design This study uses survey data from two Swedish samples. Sample 1 consists of 267 students ( $78.7 \%$ women) with a mean age of $24.5(S D=6.1)$. Sample 2 consists of 195 primary care patients (56.9\% women) with a mean age of $45.3(S D=17.7)$.

Results The number of participants who preferred online treatment was higher if seeking psychological help for a perceived stigmatized problem compared to mental health problems in general. The odds ratios for choosing treatment online over face-to-face were 6.41, 95\% Cl [4.05, 10.14] in Sample 1 and 11.19, 95\% Cl [5.29, 23.67] in Sample 2. In addition, findings suggest that higher levels of helpseeking self-stigma predicted higher intention to seek treatment online compared to face-to-face.

Conclusions Our results suggest that online interventions may facilitate help-seeking among individuals deterred by stigma.

KEYWORDS

E-mental health, help-seeking, Internet based intentions, mental health services, online therapy
\end{abstract}

\section{1 | INTRODUCTION}

A large number of people suffering from psychological distress do not receive professional help (Whiteford, Ferrari, Degenhardt, Feigin, \& Vos, 2015; Wittchen et al., 2011). It has been argued that most of the unmet need for treatment in high-income countries can be attributed to a reluctance to seek help because of stigma, rather than a lack of care provision (Clement et al., 2012). Therefore, efforts to decrease help-seeking barriers related to stigma are important in order to improve access to care (Patel et al., 2016).

Stigma is a term used to describe a process in which an attribute marks an individual as different and devalued in a particular social context (Bos, Pryor, Reeder, \& Stutterheim, 2013). Being exposed to stigma may lead to aversive 
consequences for the individual, including self-stigma. Self-stigma refers to identification with specific negative stereotypes, for example, those related to mental health problems (Corrigan, 2004). This kind of self-stigma may result in shame, self-devaluative thoughts, and fear of social exclusion, all of which may serve as a barrier while striving toward important life goals (Luoma, Kohlenberg, Hayes, Bunting, \& Rye, 2008). Mental health related self-stigma has been found to exacerbate psychosocial impairment and to have an overall detrimental effect on self-care behaviors (Livingston \& Boyd, 2010).

Help-seeking is regarded as a type of self-care behavior with the purpose of obtaining assistance with, for example, a mental health problem (Rickwood \& Thomas, 2012). In a recent meta-analysis, mental health related self-stigma shows a small negative median correlation with intentions to seek formal mental health services (Clement et al., 2015).

Ethnic minorities, males, and youth were deterred from help-seeking by stigma to an even larger degree. In another study, both self-stigma related to having a mental health problem and self-stigma related to seeking help predicted feelings of shame. However, only help-seeking self-stigma predicted attitudes toward seeking help (Tucker et al., 2013). This finding indicates a specific stigma related to the act of seeking professional help for mental health problems.

There are several possible links between self-stigma and avoidance of seeking help. Refraining from seeking formal mental health services serves to temporarily reduce anticipated negative social and emotional consequences such as feeling embarrassed when talking to a care provider (Clement et al., 2015; Henderson, Evans-Lacko, \& Thornicroft, 2013), as well as protecting a sense of perceived self-worth (Corrigan, 2004; Schomerus \& Angermeyer, 2008). However, early treatment may reduce the persistency and severity of primary disorders as well as prevent the onset of secondary conditions (Kessler et al., 2007). Therefore, efforts aimed at enabling individuals perceiving stigma to seek professional help is a worthwhile contribution to mental health.

One way to enable help-seeking among individuals affected by stigma is to provide anonymous mental health services (Clement et al., 2015). For example, electronic mental health (e-mental health) interventions may be experienced as less stigmatizing as compared to psychological treatment delivered face-to-face (Griffiths, Lindenmeyer, Powell, Lowe, \& Thorogood, 2006; Spurgeon \& Wright, 2010). E-mental health includes the use of Internet to deliver treatment via computers, mobile phones, and tablets. Such interventions are often self-instructing and may be used in a private setting. Therapist guidance is usually provided in a text-message form (Andersson \& Titov, 2014). Actual eye contact with a therapist is usually not required. Hence, individuals with stigma-related symptoms who are reluctant to seek face-to-face treatment may find it easier to use online interventions.

Although e-mental health interventions may improve access to treatment, low take-up rates are reported in routine care settings (Kaltenthaler et al., 2008). One limitation of online treatment may be unfavorable believes with regard to its helpfulness. In a study among adults in the United Kingdom, perceived helpfulness and intention to use online interventions were lower as compared to face-to-face treatment (Musiat, Goldstone, \& Tarrier, 2014).

In sum, online interventions may reduce the effects of stigma for help-seeking behavior and thereby improve overall access to professional services. However, few empirical studies have investigated if online interventions represent a less stigmatizing source of treatment as compared to face-to-face delivery (Musiat \& Tarrier, 2014). The aim of this study is to investigate the impact of help-seeking self-stigma on the preference and intention to seek psychological treatment delivered online as compared to face-to-face. We investigated one sample of college students and one sample of primary health care patients, both representing potential target populations for online interventions. The first sample of undergraduate students represents a high-risk population for mental distress (Said, Kypri, \& Bowman, 2013; Stallman, 2010). Online interventions have been used to enable help-seeking behavior among undergraduate students who are reluctant to seek formal sources of help (Ryan, Shochet, \& Stallman, 2010). The second sample composed of patients within primary care because many people receive mental health treatment in a primary care context.

More specifically, we aim to investigate if the proportions of participants who preferred online versus face-to-face treatment are different depending on the nature of the problem. Assuming that online interventions represent a less stigmatizing source of help, we hypothesize that a larger proportion of the participants will prefer treatment online when seeking help for a problem they perceive as stigmatized compared to mental health problems in general. Also, 
we will investigate if help-seeking self-stigma predicts a difference in intention to seek psychological treatment online as compared to face-to-face, while controlling for age, gender, country of birth, psychological distress, mental health self-stigma, and treatment expectancy. A positive correlation between help-seeking self-stigma and higher intention to seek online interventions as compared to face-to-face is expected.

\section{2 | METHOD}

\section{1 | Participants}

Inclusion criteria required that participants were at least 18 years old and were able to read and write in Swedish.

Sample 1. The first sample consisted of undergraduate students $(N=267)$. Recruitment took place at a university campus at the faculties of social sciences, medicine, and pharmacy. The mean age of the participants was 24.5 years $(S D=6.1)$. The majority was female $(78.7 \%)$ and most participants used the Internet daily $(97.8 \%)$. About one third (29.2\%) had previously sought help for a mental health problem, and the treatment had predominantly been delivered face-to-face (91\%).

Sample 2. The second sample consisted of patients recruited from three primary health care clinics $(N=195)$. The mean age in this sample was 45.3 years $(S D=17.7)$ and $56.9 \%$ were female. The majority used the Internet daily (92.3\%). More than one third (38.4\%) of the participants had previously sought help for a mental health condition, and the treatment had predominantly been delivered face-to-face (81\%). Further demographic characteristics are displayed in Table 1.

\section{2 | Measures}

\subsection{1 | Current psychological distress}

The Depression Anxiety and Stress Scale-21 (DASS-21; Lovibond \& Lovibond, 1995) is used to measure current psychological distress. The scale consists of 21 items rated on a 4-point scale from 0 (does not apply to me at all) to 3 (applies to me most of the time). The scale has three subscales with an equal number of items: depression (e.g., "thought life was meaningless"); anxiety (e.g., "felt I was close to panic"); and stress (e.g., "found it difficult to relax"). Raw scores are doubled to facilitate comparison with normative data established with DASS-42 (Gloster et al., 2008). Higher scores indicate higher level of distress. DASS-21 has shown excellent internal consistency and good construct validity (Henry $\&$ Crawford, 2005; Osman et al., 2012). In the current study, the internal consistency was $\alpha=.93$ in both samples.

\subsection{2 | Mental health self-stigma}

The Self-Stigma of Mental IIIness Scale (SSOMI; Tucker et al., 2013) is used to measure mental health self-stigma. The scale consists of 10 items (e.g., "I would feel inadequate if I had a mental illness") rated on a 5-point scale from 1 (totally disagree) to 5 (totally agree). Four items are reversed when scoring. Higher scores indicate higher levels of self-stigma. SSOMI has demonstrated good reliability and convergent validity (Tucker et al., 2013). In this study, internal consistencies in Samples 1 and 2 were $\alpha=.85$ and $\alpha=.87$, respectively.

\subsection{3 | Help-seeking self-stigma}

The self-Stigma of Seeking Psychological Help Scale (SSOSH; Vogel et al., 2013) is used to measure help-seeking selfstigma. The scale consists of 10 items (e.g., "If I went to a therapist, I would be less satisfied with myself") rated on a 5 -point scale from 1 (totally disagree) to 5 (totally agree). Five items are reversed when scoring. Higher scores indicate higher levels of self-stigma. SOSSH has demonstrated adequate internal consistency, test-retest reliability, and predictive validity of actual help-seeking behavior (Vogel et al., 2013). In this study, internal consistencies in Samples 1 and 2 were $\alpha=.84$ and $\alpha=.85$, respectively. SSOMI and SSOSH were translated into Swedish using a standard back translation procedure. 
TABLE 1 Demographic characteristics by sample

\begin{tabular}{|c|c|c|}
\hline Characteristics & $\begin{array}{l}\text { Sample } 1 \\
(N=267) \\
n(\%)\end{array}$ & $\begin{array}{l}\text { Sample } 2 \\
(N=195) \\
n(\%)\end{array}$ \\
\hline Age & $24.5^{a}(6.1)^{b}$ & $45.3^{\mathrm{a}}(17.7)^{\mathrm{b}}$ \\
\hline Female & $210(78.7)$ & $111(56.9)$ \\
\hline \multicolumn{3}{|l|}{ Occupation } \\
\hline Employed & $7(2.6)$ & $118(60.5)$ \\
\hline Student & $258(96.6)$ & $27(13.8)$ \\
\hline Unemployed & $1(0.4)$ & $5(2.6)$ \\
\hline Retired & $1(0.4)$ & 35 (17.9) \\
\hline Sick leave & $0(0)$ & $4(2.1)$ \\
\hline \multicolumn{3}{|l|}{ Education (completed) } \\
\hline Elementary/high school & $200(74.9)$ & $79(40.5)$ \\
\hline University & $67(25.1)$ & $112(57.4)$ \\
\hline \multicolumn{3}{|l|}{ Civil status } \\
\hline Single & $124(46.4)$ & $55(28.2)$ \\
\hline In a relationship & $143(53.6)$ & $134(68.7)$ \\
\hline \multicolumn{3}{|l|}{ Country of birth } \\
\hline Sweden & $237(88.8)$ & $152(77.9)$ \\
\hline Other & $30(11.2)$ & $39(20.0)$ \\
\hline \multicolumn{3}{|l|}{ Internet use } \\
\hline Daily & $261(97.8)$ & $180(92.3)$ \\
\hline Less than daily & $6(2.2)$ & $11(5.6)$ \\
\hline \multicolumn{3}{|c|}{ Previous mental health service use } \\
\hline Internet & $3(1.1)$ & $3(1.5)$ \\
\hline Face-to-face & $71(26.6)$ & $61(31.3)$ \\
\hline Other & $4(1.5)$ & $11(5.6)$ \\
\hline
\end{tabular}

aMean.

${ }^{\mathrm{b}} \mathrm{SD}$.

\subsection{4 | Treatment preference}

Treatment preference is measured with forced choice items. Online treatment was described as a form of psychological treatment delivered through the Internet, typically involving educational material, homework assignments and sometimes support by a therapist via e-mail or telephone. First, respondents were asked to indicate a preference for the delivery of psychological treatment if the need arose now of in the future. The choices of delivery given to participants were as follows: online, face to face, and neither. Second, participants were asked the same question but now with regard to seeking help for a problem they would feel embarrassed about (stigmatized problem). As what is perceived as a stigmatized problem may vary between social contexts, examples of specific problems were not given. The choices of delivery given to participants were as follows: online, face to face, and neither. Participants also had the option to indicate that they would not feel embarrassed about any problem.

\subsection{5 | Treatment expectancy}

The perceived helpfulness of psychological treatment delivered online and face-to-face is measured with regard to four areas: psychological distress, lifestyle-related problems, interpersonal problems, and personal crisis. Items are rated on 
a 7-point scale from 1 (not very helpful) to 7 (very helpful). Because of a clerical error, the items were rated on a 6-point scale in Sample 2. Items showed adequate internal consistencies in both Samples 1 and 2 regarding both online $(\alpha=.74$, $.86)$, and face-to-face treatment $(\alpha=.87, .89)$.

\subsubsection{Help-seeking intentions}

To measure help-seeking intentions, four items based on the Intentions to Seek Counseling Inventory (ISCl; Cash, Begley, McCown, \& Weise, 1975) are used. Participants were asked how likely they would be to seek psychological treatment online and face-to-face in regard to the same four areas used to measure treatment expectancy. Items were rated on a 7-points scale from 1 (very unlikely) to 7 (very likely). Because of a clerical error, the items were rated on a 6-point scale in Sample 2. The original ISCI is widely used and has shown satisfactory reliability and construct validity (Wei et al., 2015). Items showed adequate internal consistencies in both Samples 1 and 2 regarding both online $(\alpha=.82$, .89), and face-to-face treatment $(\alpha=.86, .88)$.

\section{3 | Procedure}

Participants were recruited by advertisement on notice boards in a university campus and in primary health care clinics. Recruitment visits to lecture rooms and waiting rooms were also made. Willing participants signed an informed consent form before completing the survey. They received information that the aim of the study was to investigate attitudes toward seeking professional psychological help. Included students were referred to a secured web-based survey, whereas primary health care patients completed a paper and pencil survey. Only one response per email address was allowed in the web-based survey. The survey took approximately $15 \mathrm{~min}$ to complete. Participants received a lottery ticket as compensation for responding. Data collection was conducted in Sweden between 2014 and 2015. The study was approved by the Regional Ethical Review Board in Uppsala, Sweden.

\section{4 | Statistical analyses}

One missing value per individual was allowed when calculating the mean scores of scales including four items. Two missing values per individual were allowed on scales with 10 items or more. Individual scores were calculated for the variables Treatment Expectancy Difference and Treatment Intention Difference by subtracting the mean related to face-to-face interventions from the mean related to online interventions. For example, individuals who score a higher intention to seek treatment online compared to face-to-face obtain a positive score and vice versa.

McNemar's test and odds ratio (OR) were used to analyze differences in treatment preference. Multiple linear regressions were used to investigate if help-seeking self-stigma predicted a difference in the intention to seek psychological treatment online as compared to face-to-face while controlling for age, gender, country of birth, psychological distress, mental health self-stigma, and treatment expectancy. Intercorrelations between the included variables were calculated using two-tailed Pearson product-moment correlation, point-biserial correlations, and $\chi^{2}$ test of association. Assessment of basic assumptions of multiple linear regression was conducted. The variables were entered into the regression model by forced entry. Multivariate outliers and influential cases were investigated according to recommendations by Stevens (1984). The statistical software package IBM SPSS 24.0 was used to analyze data.

\section{3 | RESULTS}

We investigated if the proportions of participants who preferred online versus face-to-face treatment were different depending on the nature of the problem. Approximately four of five participants (78.3\% in Sample 1 and $84.6 \%$ in Sample 2) preferred face-to-face treatment if seeking help for mental health problems in general. The treatment preference for a perceived stigmatizing problem showed a different response pattern. More participants (43.4\%) preferred online treatment over face-to-face $(30.3 \%)$ in Sample 1 when a perceived stigmatized problem was considered. In 
TAB LE 2 Treatment preference by sample

\begin{tabular}{|lcc|}
\hline Sample & $\begin{array}{l}\text { General mental health problem } \\
n(\%)\end{array}$ & $n(\%)$ \\
\hline Sample $1(N=267)$ & & $116(43.4)$ \\
\hline Online & $41(15.4)$ & $81(30.3)$ \\
\hline Face-to-face & $209(78.3)$ & $18(6.7)$ \\
\hline No help & $17(6.4)$ & $36(13.5)$ \\
\hline Not embarrassed & & $16(6.0)$ \\
\hline Missing & $0(0.0)$ & $63(32.3)$ \\
\hline Sample $2(N=195)$ & $12(6.2)$ & $86(44.1)$ \\
\hline Online & $165(84.6)$ & $9(4.6)$ \\
\hline Face-to-face & $13(6.7)$ & $31(15.9)$ \\
\hline No help & & $6(3.1)$ \\
\hline Not embarrassed & $5(2.6)$ & \\
\hline Missing & & \\
\hline
\end{tabular}

Sample 2, one third of the participants (32.3\%) preferred online treatment and $44.1 \%$ still preferred face-to-face treatment (see Table 2).

McNemar's test was used to further analyze difference in treatment preference. Only participants who indicated a preference for online or face-to-face treatment were included in the analysis. Results showed statistically significant differences in both Sample $1\left(\chi^{2}(1)=19.5, p<.001\right)$ and in Sample $2\left(\chi^{2}(1)=13.1, p<.001\right)$. Eighty-two participants (42.1\%) in Sample 1 changed their preference from face-to-face to online treatment if seeking help for a perceived stigmatized problem. Seventy-eight participants preferred face-to-face (39.6\%) and 33 (16.8\%) preferred online treatment regardless of the nature of the problem. Only three participants (1.5\%) changed their preference from online to face-to-face treatment. Participants were 6.41 times more likely to choose treatment online over treatment face-toface if seeking help for a perceived stigmatized problem compared to a mental health problems in general, OR $=6.41$, Cl 95\% [4.05, 10.14].

Eighty-five participants (57.8\%) in Sample 2 preferred treatment face-to-face regardless of the nature of the problem. Fifty-three participants (36.1\%) changed their preference from face-to-face to online treatment if seeking help for a perceived stigmatized problem. Nine participants (6.1\%) preferred online treatment regardless of the nature of the problem. Participants were 11.19 times more likely to choose treatment online over treatment face-to-face if seeking help for a perceived stigmatized problem compared to a mental health problems in general, OR $=11.19, \mathrm{Cl} 95 \%[5.29$, 23.67].

Moreover, we investigated if help-seeking self-stigma predicted a difference in intention to seek psychological treatment online as compared to face-to-face, while controlling for age, gender, country of birth, psychological distress, mental health self-stigma, and treatment expectancy (see Table 3 for descriptive statistics).

As shown in Table 3, participants reported lower treatment expectancy and intention to seek treatment online compared to face-to-face, which was reflected in negative mean difference scores in both samples.

Treatment Intention Difference was positively correlated with help-seeking self-stigma and Treatment Expectancy Difference in both samples. Treatment Intention Difference also showed a positive correlation with psychological distress in Sample 1 and negative correlations with age and country of birth in Sample 2 (Table 4).

Investigation of the basic assumptions supported the validity of the multiple linear regression models. Tolerance scores were greater than 0.2 and variance inflation factor (VIF) scores were below 10. This indicates that multicollinearity was not a concern (Menard, 1995; Myers, 1990). Cases identified as either outliers or influential were identified and removed. No meaningful changes regarding the overall model or the contribution of the separate predictors were observed when the multiple linear regressions were remodeled without outliers and influential cases. 
TABLE 3 Descriptive statistics by sample

\begin{tabular}{|c|c|c|c|c|}
\hline \multirow[b]{2}{*}{ Variable } & \multicolumn{2}{|c|}{ Sample 1} & \multicolumn{2}{|c|}{ Sample 2} \\
\hline & M & $S D$ & M & $S D$ \\
\hline DASS-21 Total & 30.5 & 23.9 & 22.0 & 21.6 \\
\hline DASS-21 Depression & 10.6 & 10.4 & 6.6 & 8.4 \\
\hline DASS-21 Anxiety & 6.3 & 7.6 & 5.0 & 6.3 \\
\hline DASS-21 Stress & 13.6 & 9.3 & 10.4 & 9.6 \\
\hline SSOMI & 3.4 & 0.7 & 3.1 & 0.8 \\
\hline SSOSH & 2.7 & 0.7 & 2.3 & 0.7 \\
\hline Expectancy Online ${ }^{a}$ & 3.5 & 1.2 & 3.0 & 1.2 \\
\hline Expectancy Face-to-Face ${ }^{a}$ & 5.5 & 1.1 & 5.1 & 0.9 \\
\hline Treatment Expectancy Difference ${ }^{a}$ & -2.1 & 1.4 & -2.1 & 1.4 \\
\hline Intention Online ${ }^{a}$ & 2.8 & 1.5 & 2.7 & 1.4 \\
\hline Intention Face-to-Face ${ }^{a}$ & 4.1 & 1.6 & 4.4 & 1.3 \\
\hline Treatment Intention Difference ${ }^{a}$ & -1.3 & 2.1 & -1.7 & 1.9 \\
\hline
\end{tabular}

Note. Sample 1, $n=246-267$ and Sample 2, $n=189-194$. DASS-21 = Depression Anxiety and Stress Scale-21; SSOMI = SelfStigma of Mental IIIness Scale; SSOSH = Self-Stigma of Seeking Psychological Help Scale; Expectancy Online = treatment expectancy of online treatment; Expectancy Face-to-Face = treatment expectancy of face-to-face treatment; Treatment Expectancy Difference = difference scores between expectancy of online and face-to-face treatment; Intention online = intention to seek online treatment; Intention face-to-face = intention to seek treatment face-to-face; Treatment Intention Difference $=$ difference scores between intentions to seek treatment online compared to face-to-face.

a Items were rated on a 7-point scale in Sample 1 and a 6-points scale in Sample 2.

TABLE 4 Summary of intercorrelations by sample

\begin{tabular}{|lllllllll|}
\hline Variable & 1 & 2 & 3 & 4 & 5 & 6 & 7 & 8 \\
\hline 1. Age & - & .11 & $-21^{* *}$ & $-.14^{*}$ & -.14 & -.07 & -.02 & -.06 \\
\hline 2. Gender & .02 & - & -.07 & -.12 & -.05 & .09 & -.04 & .06 \\
\hline 3. Country of birth & -.14 & -.02 & - & .04 & -.09 & -.03 & .09 & -.06 \\
\hline 4. DASS-21 & $-.20^{* *}$ & -.08 & .05 & - & .10 & $.14^{*}$ & .07 & $.18^{* *}$ \\
\hline 5. SSOMI & -.06 & .03 & .04 & $.16^{*}$ & - & $.56^{* * *}$ & -.03 & .10 \\
\hline 6. SSOSH & -.01 & $.19^{*}$ & .09 & .11 & $.44^{* * *}$ & - & .05 & $.21^{* *}$ \\
\hline 7. Expectancy & -.09 & -.12 & -.06 & .11 & -.06 & .06 & - & $.55^{* * *}$ \\
\hline 8. Intention & $-.16^{*}$ & .05 & $-.18^{*}$ & -.01 & -.03 & $.17^{*}$ & $.59^{* * *}$ & - \\
\hline
\end{tabular}

Note. Intercorrelations in Sample 1 ( $n=246-267)$ are presented above the diagonal, and below the diagonal in Sample 2 ( $n=182-192)$. Gender ( $1=$ female and $2=$ male); country of birth $(1=$ born in Sweden and $2=$ born outside Sweden); DASS21 = Depression Anxiety and Stress Scale-21; SSOMI = Self-Stigma of Mental Illness Scale; SSOSH = Self-Stigma of Seeking Psychological Help Scale. Expectancy = Treatment Expectancy Difference; Intention = Treatment Intention Difference. ${ }^{*} p<.05,{ }^{* *} p<.01,{ }^{* * *} p<.001$.

The result of the multiple linear regression analysis showed a significant regression equation in Sample 1 , $\left(F(7,233)=22.69, p<.001, R^{2}\right.$ Adjusted $\left.=.39\right)$. The full model accounted for $39 \%$ of the variability in Treatment Intention Difference scores. Three predictors made significant contributions to the overall model. Individuals reporting higher levels of psychological distress, help-seeking self-stigma, and treatment expectancy of online interventions were more likely to report higher intentions to seek treatment online compared to face-to-face (Table 5).

The result of the multiple regression analysis showed a significant regression equation in Sample 2, ( $F(7$, $166)=15.49, p<.001, R^{2}$ Adjusted $\left.=.37\right)$. The full model accounted for $37 \%$ of the variation in Treatment Intention Difference scores. Four predictors made a significant contribution to the overall model. Individuals who were younger, 
TAB LE 5 Regression model for Treatment Intention Difference scores in Sample $1(N=241)$

\begin{tabular}{|c|c|c|c|c|c|}
\hline Variable & $B$ & SE B & $\beta$ & $t$ & $p$ \\
\hline (Constant) & -0.84 & 0.90 & & -0.94 & .348 \\
\hline Age & -0.02 & 0.21 & -.06 & -1.14 & .257 \\
\hline Gender & 0.49 & 0.27 & .07 & 1.83 & .069 \\
\hline Country of birth & -0.58 & 0.35 & -.09 & -1.66 & .099 \\
\hline DASS-21 & 0.01 & 0.00 & .15 & 2.89 & .004 \\
\hline SSOMI & 0.01 & 0.19 & .04 & 0.583 & .561 \\
\hline SSOSH & 0.04 & 0.02 & .15 & 2.13 & .034 \\
\hline Expectancy & 0.84 & 0.08 & .56 & 11.05 & $<.001$ \\
\hline
\end{tabular}

Note. DASS-21 = Depression Anxiety and Stress Scale-21; SSOMI = Self-Stigma of Mental IIIness Scale; SSOSH = Self-Stigma of Seeking Psychological Help Scale; Expectancy = Treatment Expectancy Difference. $R=.64, R^{2}=.41$. Adjusted $R^{2}=.39$. $\Delta R^{2}=.41$.

TAB LE 6 Regression model for Treatment Intention Difference scores in Sample $2(N=174)$

\begin{tabular}{|c|c|c|c|c|c|}
\hline Variable & B & SE B & $\beta$ & $t$ & $p$ \\
\hline (Constant) & .82 & 0.72 & & 1.14 & .258 \\
\hline Age & -0.01 & .007 & -.14 & -2.21 & .03 \\
\hline Gender & 0.28 & .23 & .08 & 1.20 & .234 \\
\hline Country of birth & -0.91 & .28 & -.20 & -3.22 & .002 \\
\hline DASS-21 & -0.01 & .01 & -.07 & -1.06 & .291 \\
\hline SSOMI & -0.13 & .02 & -.06 & -0.06 & .397 \\
\hline SSOSH & 0.04 & .02 & .17 & 2.53 & .012 \\
\hline Expectancy & 0.76 & .09 & .53 & 8.39 & $<.001$ \\
\hline
\end{tabular}

Note. DASS-21 = Depression Anxiety and Stress Scale-21; SSOMI = Self-Stigma of Mental IIIness Scale; SSOSH = Self-Stigma of Seeking Psychological Help Scale; Expectancy = Treatment Expectancy Difference. $R=.63, R^{2}=.40$. Adjusted $R^{2}=.37$. $\Delta R^{2}=.40$.

born in Sweden and reported higher levels of help-seeking self-stigma and treatment expectancy of online interventions were more likely to report higher intentions to seek treatment online compared to face-to-face (Table 6).

\section{4 | DISCUSSION}

The aim of this study was to investigate the impact of help-seeking self-stigma on the preference and intention to seek psychological treatment delivered online compared to face-to-face. Most students and primary care patients preferred face-to-face treatment if seeking help for mental health problems in general. In line with our hypothesis, the number of participants who preferred online treatment was higher if seeking help for a problem they perceive as stigmatized. However, the majority of primary care patients preferred face-to-face treatment regardless of the nature of the problem.

Furthermore, we expected and found that higher levels of help-seeking self-stigma predicted higher intention to seek treatment online compared to face-to-face. In line with previous findings (Tucker et al., 2013), mental health selfstigma showed no association with intention to seek help. It is worth noting that the negative association between help-seeking self-stigma and Treatment Intention Difference was low. Given this, self-stigma appears to be a complex construct that does not necessarily translate into reduced help seeking. Although some individuals are deterred by stigma, some stay unaffected (Corrigan \& Watson, 2002). The detrimental effects of self-stigma may be understood 
as both the presence of self-stigmatizing thoughts and feelings, and the avoidance strategies used by the individual to cope with these aversive experiences (Luoma et al., 2008).

Participants in this study had lower expectations on the helpfulness of online treatment than on face-to-face treatment. Unfavorable believes about the helpfulness of online treatment have previously been reported by Musiat et al. (2014). Although this study cannot establish causality between predictors and the outcome, it is worth noting that treatment expectancy was the strongest predictor of differences in intentions to seek help. These findings suggest that efforts to increase treatment expectancy may be key to improving the uptake of online treatment in routine care. It is possible that most people are unaware of the potential benefits of online treatment. Low treatment expectancy and intention to seek online interventions may also reflect a tendency to be conservative toward new and unfamiliar things.

Furthermore, higher levels of distress were associated with higher intentions to seek treatment online compared to face-to-face, but only among students. One possible explanation of this difference between samples is that participants recruited in primary care have already overcome some barriers related to help seeking. Students, on the other hand, may face instrumental barriers and stigma related to seeking traditional sources of help, and may therefore be more inclined to seek online treatment. We also found that higher age and being born outside of Sweden was associated with a lower intention to seek online interventions as compared to face-to-face among primary care patients. This difference could be the result of sample characteristics such as computer literacy and language proficiency.

This study has methodological weaknesses, which limit the conclusions and generalizations possible to make. Although included measures showed adequate internal consistency, the scales used to measure treatment expectancy and intentions have not been validated. Furthermore, the outcome measures regarding preference and treatment intention represent hypothetical questions about future behavior. According to the theory of planned behavior, intention is a reliable predictor of actual behavior (Ajzen, 1991). Intentions have been found to be a significant predictor of actual mental health service use (Ten Have et al., 2010). However, it has also been pointed out that improvements in help-seeking intentions not necessarily translate into actual behavior (Gulliver, Griffiths, Christensen, \& Brewer, 2012). Another possible limitation is that the order of the items measuring preferences and intentions to seek help may have affected the participants' ratings. To avoid a response artifact, items regarding seeking help for a problem perceived as stigmatized and for mental health problems in general could have been randomized.

The level of education and the gender distribution in the sample of primary care patients are comparable to what has been found in a previous study using data from the Primary care register in Sweden (Lejtzén, Sundquist, Sundquist, $\& \mathrm{Li}$, 2014). This supports the representativeness of the sample for primary care patients in Sweden. However, the majority of participants in both samples had a university education, which might restrict the generalizability of the results to populations with lower educational level.

Other sample characteristics relate to computer use and previous experience with psychological treatment. Almost all participants report using the Internet on a daily basis. Although some participants have previous experience of psychological face-to-face treatment, only a small minority have previous experience of e-mental health services. It is possible that previous experience with psychological treatment, computer use, and literacy affect attitudes toward the different treatment formats.

In sum, the results of this study imply that patient preferences and low expectations about the helpfulness of online treatment may limit the uptake in routine care. Strategies to improve treatment expectancy may include communication about the effectiveness and safety of e-mental health services (Christensen, Reynolds, \& Griffiths, 2011). Our results also suggest that online interventions may facilitate help-seeking among individuals deterred by stigma. It is possible that online interventions may be used to reach individuals reluctant to seek face-to-face treatment. However, more research is needed about the association between self-stigma and actual help-seeking online. Furthermore, more knowledge is needed to understand more about for whom online interventions are acceptable and how online interventions can best match the needs of intended users. For example, mixed-methods research designs about the acceptability and use of online interventions may be a complement to treatment outcome studies (Van Gemert-Pijnen et al., 2011). Development of a validated measure of barriers and facilitators specifically related to e-mental health services could be useful tools to investigate for whom and in which contexts online interventions are suitable. 


\section{ORCID}

Emma Wallin (iD http://orcid.org/0000-0003-3548-8387

\section{REFERENCES}

Ajzen, I. (1991). The theory of planned behavior. Organizational Behavior and Human Decision Processes, 50(2), $179-211$. https://doi.org/10.1016/0749-5978(91)90020-T

Andersson, G., \& Titov, N. (2014). Advantages and limitations of Internet-based interventions for common mental disorders. World Psychiatry, 13(1), 4-11. https://doi.org/10.1002/wps.20083

Bos, A. E. R., Pryor, J. B., Reeder, G. D., \& Stutterheim, S. E. (2013). Stigma: Advances in theory and research. Basic and Applied Social Psychology, 35(1), 1-9. https://doi.org/10.1080/01973533.2012.746147

Cash, T. F., Begley, P. J., McCown, D. A., \& Weise, B. C. (1975). When counselors are heard but not seen: Initial impact of physical attractiveness. Journal of Counseling Psychology, 22(4), 273-279. https://doi.org/10.1037/h0076730

Christensen, H., Reynolds, J., \& Griffiths, K. M. (2011). The use of e-health applications for anxiety and depression in young people: Challenges and solutions. Early Intervention in Psychiatry, 5, 58-62. https://doi.org/10.1111/j.1751-7893.2010. 00242.x

Clement, S., Brohan, E., Jeffery, D., Henderson, C., Hatch, S. L., \& Thornicroft, G. (2012). Development and psychometric properties the Barriers to Access to Care Evaluation scale (BACE) related to people with mental ill health. BMC Psychiatry, 12(1), 36. https://doi.org/10.1186/1471-244X-12-36

Clement, S., Schauman, O., Graham, T., Maggioni, F., Evans-Lacko, S., Bezborodovs, N., ... Thornicroft, G. (2015). What is the impact of mental health-related stigma on help-seeking? A systematic review of quantitative and qualitative studies. Psychological Medicine, 45(1), 11-27. https://doi.org/10.1017/S0033291714000129

Corrigan, P. (2004). How stigma interferes with mental health care. American Psychologist, 59(7), 614-625. https://doi.org/10.1037/0003-066X.59.7.614

Corrigan, P. W., \& Watson, A. C. (2002). The paradox of self-stigma and mental illness. Clinical Psychology: Science and Practice, 9(1), 35-53. https://doi.org/10.1093/clipsy/9.1.35

Gloster, A. T., Rhoades, H. M., Novy, D., Klotsche, J., Senior, A., Kunik, M., \& Stanley, M. A. (2008). Psychometric properties of the Depression Anxiety and Stress Scale-21 in older primary care patients. Journal of Affective Disorders, 110(3), 248-259. https://doi.org/10.1016/j.jad.2008.01.023

Griffiths, F., Lindenmeyer, A., Powell, J., Lowe, P., \& Thorogood, M. (2006). Why are health care interventions delivered over the internet? A systematic review of the published literature. Journal of Medical Internet Research, 8(2), e10. https:// doi.org/10.2196/jmir.8.2.e10

Gulliver, A., Griffiths, K. M., Christensen, H., \& Brewer, J. L. (2012). A systematic review of help-seeking interventions for depression, anxiety and general psychological distress. BMC Psychiatry, 12(1), 81. https://doi.org/10.1186/ 1471-244X-12-81

Henderson, C., Evans-Lacko, S., \& Thornicroft, G. (2013). Mental illness stigma, help seeking, and public health programs. American Journal of Public Health, 103(5), 777-780. https://doi.org/10.2105/AJPH.2012.301056

Henry, J. D., \& Crawford, J. R. (2005). The short-form version of the Depression Anxiety Stress Scales (DASS-21): Construct validity and normative data in a large non- sample. British Journal of Clinical Psychology, 44(2), $227-239$. https://doi.org/10.1348/014466505X29657

Kaltenthaler, E., Sutcliffe, P., Parry, G., Beverley, C., Rees, A., \& Ferriter, M. (2008). The acceptability to patients of computerized cognitive behaviour therapy for depression: A systematic review. Psychological Medicine, 38(11), 1521. https://doi.org/10.1017/S0033291707002607

Kessler, R. C., Angermeyer, M., Anthony, J. C., DE Graaf, R., Demyttenaere, K., Gasquet, I., ... Ustün, T. B. (2007). Lifetime prevalence and age-of-onset distributions of mental disorders in the World Health Organization's World Mental Health Survey Initiative. World Psychiatry: Official Journal of the World Psychiatric Association (WPA), 6(3), 168176.

Lejtzén, N., Sundquist, J., Sundquist, K., \& Li, X. (2014). Depression and anxiety in Swedish primary health care: Prevalence, incidence, and risk factors. European Archives of Psychiatry and Clinical Neuroscience, 264(3), 235-245. https:// doi.org/10.1007/s00406-013-0422-3.

Livingston, J. D., \& Boyd, J. E. (2010). Correlates and consequences of internalized stigma for people living with mental illness: A systematic review and meta-analysis. Social Science \& Medicine, 71(12), 2150-2161. https://doi.org/ 10.1016/j.socscimed.2010.09.030 
Lovibond, P. F., \& Lovibond, S. H. (1995). The structure of negative emotional states: Comparison of the Depression Anxiety Stress Scales (DASS) with the Beck Depression and Anxiety Inventories. Behaviour Research and Therapy, 33(3), 335-343. https://doi.org/10.1016/0005-7967(94)00075-U

Luoma, J. B., Kohlenberg, B. S., Hayes, S. C., Bunting, K., \& Rye, A. K. (2008). Reducing self-stigma in substance abuse through acceptance and commitment therapy: Model, manual development, and pilot outcomes. Addiction Research \& Theory, 16(2), 149-165. https://doi.org/10.1080/16066350701850295

Menard, S. (1995). Applied Logistic Regression Analysis: Sage University Series on Quantitative Applications in the Social Sciences. Thousand Oaks, CA: Sage.

Musiat, P., Goldstone, P., \& Tarrier, N. (2014). Understanding the acceptability of e-mental health-Attitudes and expectations towards computerized self-help treatments for mental health problems. BMC Psychiatry, 14(1), 109. https://doi.org/10.1186/1471-244X-14-109

Musiat, P., \& Tarrier, N. (2014). Collateral outcomes in e-mental health: A systematic review of the evidence for added benefits of computerized cognitive behavior therapy interventions for mental health. Psychological Medicine, 44(15), 3137-3150. https://doi.org/10.1017/S0033291714000245

Myers (1990). 1990. Classical and Modern Regression with Applications (2nd ed.). Boston: Duxbury.

Osman, A., Wong, J. L., Bagge, C. L., Freedenthal, S., Gutierrez, P. M., \& Lozano, G. (2012). The Depression Anxiety Stress Scales21 (DASS-21): Further examination of dimensions, scale reliability, and correlates. Journal of Clinical Psychology, 68(12), 1322-1338. https://doi.org/10.1002/jclp.21908

Patel, V., Chisholm, D., Parikh, R., Charlson, F. J., Degenhardt, L., Dua, T., ... Whiteford, H. (2016). Addressing the burden of mental, neurological, and substance use disorders: Key messages from disease control priorities, 3rd edition. Lancet, 387(10028), 1672-1685. https://doi.org/10.1016/S0140-6736(15)00390-6

Rickwood, D., \& Thomas (2012). Conceptual measurement framework for help-seeking for mental health problems. Psychology Research and Behavior Management, 5, 173. https://doi.org/10.2147/PRBM.S38707

Ryan, M. L., Shochet, I. M., \& Stallman, H. M. (2010). Universal online interventions might engage psychologically distressed university students who are unlikely to seek formal help. Advances in Mental Health, 9(1), 73-83. https://doi.org/ 10.5172/jamh.9.1.73

Said, D., Kypri, K., \& Bowman, J. (2013). Risk factors for mental disorder among university students in Australia: Findings from a web-based cross-sectional survey. Social Psychiatry and Psychiatric Epidemiology, 48(6), 935-944. https://doi.org/ 10.1007/s00127-012-0574-x

Schomerus, G., \& Angermeyer, M. C. (2008). Stigma and its impact on help-seeking for mental disorders: What do we know? Epidemiologia E Psichiatria Sociale, 17(1), 31-37.

Spurgeon, J. A., \& Wright, J. H. (2010). Computer-assisted cognitive-behavioral therapy. Current Psychiatry Reports, 12(6), 547552. https://doi.org/10.1007/s11920-010-0152-4

Stallman, H. M. (2010). Psychological distress in university students: A comparison with general population data. Australian Psychologist, 45(4), 249-257. https://doi.org/10.1080/00050067.2010.482109

Stevens, J. P. (1984). Outliers and influential data points in regression analysis. Psychological Bulletin, 95(2), 334-344. https:// doi.org/10.1037/0033-2909.95.2.334

Ten Have, M., de Graaf, R., Ormel, J., Vilagut, G., Kovess, V., \& Alonso, J. (2010). Are attitudes towards mental health help-seeking associated with service use? Results from the European Study of Epidemiology of Mental Disorders. Social Psychiatry and Psychiatric Epidemiology, 45(2), 153-163. https://doi.org/10.1007/s00127-0090050-4

Tucker, J. R., Hammer, J. H., Vogel, D. L., Bitman, R. L., Wade, N. G., \& Maier, E. J. (2013). Disentangling self-stigma: Are mental illness and help-seeking self-stigmas different? Journal of Counseling Psychology, 60(4), 520-531. https://doi.org/ 10.1037/a0033555

Van Gemert-Pijnen, J. E. W. C., Nijland, N., van Limburg, M., Ossebaard, H. C., Kelders, S. M., Eysenbach, G., \& Seydel, E. R. (2011). A holistic framework to improve the uptake and impact of eHealth technologies. Journal of Medical Internet Research, 13(4), e111. https://doi.org/10.2196/jmir.1672

Vogel, D. L., Armstrong, P. I., Tsai, P.-C., Wade, N. G., Hammer, J. H., Efstathiou, G., \& Topkaya, N. (2013). Cross-cultural validity of the Self-Stigma of Seeking Help (SSOSH) scale: Examination across six nations. Journal of Counseling Psychology, 60(2), 303-310. https://doi.org/10.1037/a0032055

Wei, Y., McGrath, P. J., Hayden, J., Kutcher, S., Costello, E., Mustillo, S., \& Fishbein, M. (2015). Mental health literacy measures evaluating knowledge, attitudes and help-seeking: A scoping review. BMC Psychiatry, 15(1), 291. https://doi.org/10.1186/s12888-015-0681-9 
Whiteford, H. A., Ferrari, A. J., Degenhardt, L., Feigin, V., \& Vos, T. (2015). The global burden of mental, neurological and substance use disorders: An analysis from the Global Burden of Disease Study 2010. PLoS One, 10(2), e0116820. https://doi.org/10.1371/journal.pone.0116820

Wittchen, H. U., Jacobi, F., Rehm, J., Gustavsson, A., Svensson, M., Jönsson, B., .. Steinhausen, H.-C. (2011). The size and burden of mental disorders and other disorders of the brain in Europe 2010. European Neuropsychopharmacology, 21(9), 655-679. https://doi.org/10.1016/j.euroneuro.2011.07.018

How to cite this article: Wallin E, Maathz P, Parling T, Hursti T. Self-stigma and the intention to seek psychological help online compared to face-to-face. J Clin Psychol. 2018;1-12. https://doi.org/10.1002/jclp.22583 